\title{
Trace Element Water Improves the Antioxidant Activity of Buckwheat (Fagopyrum esculentum Moench) Sprouts
}

\author{
Chia-Ling Liu ${ }^{\dagger}$ Yih-Shyuan Chen, $^{\dagger}$ JoAn-Hwa Yang $^{\dagger}$ \\ Been-Huang Chiang, ${ }^{\ddagger}$ and Cheng-Kuang Hsu* ${ }^{*} \S$
}

\begin{abstract}
Department of Food Science, Nutrition, and Nutraceutical Biotechnology, Shih Chien University, 70, Ta-chih Street, Taipei 104, Taiwan, ROC, Institute of Food Science and Technology, National Taiwan University, No. 1, Sec. 4, Roosevelt Road, Taipei 106, Taiwan, ROC, and Department of Applied Life Science, Asia University, No. 500, Lioufeng Road, Wufeng Shiang, Taichung 413, Taiwan, ROC
\end{abstract}

\begin{abstract}
Buckwheat (Fagopyrum esculentum Moench) was grown in trace element water (TEW) $(100,200$, 300,400 , and $500 \mathrm{ppm}$ ) and deionized water (DIW) to evaluate whether the beneficial effects of trace elements on the antioxidant activity could be accomplished with the supplement of TEW. At $300 \mathrm{ppm}$, TEW significantly increased the $\mathrm{Cu}, \mathrm{Zn}, \mathrm{Mn}$, and Fe contents in buckwheat sprout but not the Se content. However, the levels of rutin, isoorientin, vitexin, and isovitexin did not differ between buckwheat sprouts grown in TEW and DIW. The ethanolic extract from buckwheat sprout grown in $300 \mathrm{ppm}$ of TEW showed higher ferrous ion chelating activity and inhibitory activity toward lipid peroxidation than that grown in DIW. The extract in the TEW group also enhanced intracellular superoxide dismutase activity and lowered reactive oxygen species and superoxide anion in the human Hep G2 cell. It was concluded that TEW could increase the antioxidant activities of buckwheat sprouts.
\end{abstract}

KEYWORDS: Buckwheat; Fagopyrum esculentum Moench; trace element water; antioxidant; rutin

\section{INTRODUCTION}

Buckwheat is grown in many countries in Asia, Europe, and South Africa, in Canada, The United States of America, and Brazil, and in certain other places around the world. The most popular food is buckwheat noodles, very popular in Japan, China, and Italy, made from buckwheat flour-water dough. Buckwheat sprouts are used to flavor sandwiches and salads, as well as a garnish to raw fish and sushi. The presence of rutin in buckwheat is one of the main reasons for the production of different kinds of buckwheat foods (2). No rutin was found in cereals and pseudocereals except buckwheat, which can be used as a good source of dietary rutin $(3,4)$. Rutin is a secondary plant metabolite that antagonizes the increase of capillary fragility associated with hemorrhagic disease, reduces high blood pressure (5), decreases the permeability of the blood vessels and has an antioedema effect, reduces the risk of arteriosclerosis (6), and has antioxidant activity (3).

Reactive oxygen species (ROS) in the forms of superoxide anion $\left(\cdot \mathrm{O}_{2}^{-}\right)$, hydroxyl radical $(\cdot \mathrm{OH})$, and hydrogen peroxide $\left(\mathrm{H}_{2} \mathrm{O}_{2}\right)$ are generated in living organisms through many pathways. Accumulation of ROS in aerobic organisms is thought to cause

* To whom correspondence should be addressed. Tel: 886-423323456, ext 5160. Fax: 886-4-23321126. E-mail: ckhsu@ asia.edu.tw.

${ }^{\dagger}$ Shih Chien University.

\# National Taiwan University.

$\S$ Asia University. oxidative damages in cells. Oxidative damages are believed to be strongly associated with certain human diseases such as carcinogenesis, mutagenesis, aging, and atherosclerosis (1).

Trace element status is very important to maintain biological functions in all living organisms. Trace elements are involved in the antioxidant responses, inflammation, wound healing, and immune responses $(7,8)$. For the antioxidant system, several trace elements are involved in the main cellular defenses against reactive oxygen species (ROS), as cofactors of superoxide dismutase (SOD) or glutathione peroxidase (GPx) (9-11). These enzymes protect cell membranes from damage caused by the peroxidation of lipids. For example, manganese (Mn) plays a major antioxidant role, both as a Mn-SOD cofactor and as a direct ROS scavenger (12). Zinc (Zn) can stimulate the activity of SOD (13). Selenium (Se) is an essential trace element for animals and humans because of its role in GPx (14). In this study, the effect of trace element water on the antioxidant activity of buckwheat sprout was determined. Measurement of antioxidant activities included reducing power, DPPH radical scavenging activity, ferrous ion chelating activity, and inhibitory activity toward lipid peroxidation, as well as intracellular antioxidant enzyme activities, reactive oxygen species, and superoxide anion in the human Hep G2 cell.

\section{MATERIALS AND METHODS}

Materials. Buckwheat (Fagopyrum esculentum Moench) seed was domestic from Taiwan and obtained from the Taichung District 
Agricultural Research and Extension Station, Council of Agriculture Executive Yuan, Taichung, Taiwan. Trace element water (TEW) was obtained from Shimanishi Kaken Co., Ltd. (Tokyo, Japan). TEW is an extract of minerals from vermiculite in liquid form with a mineral salt content close to $30 \%$ (15).

Rutin, ascorbic acid, butylated hydroxytoluene (BHT), 2',7'-dichlorofluorescein diacetate (DCFH-DA), dihydroethidium (DHE), 1,1diphenyl-2-picrylhydrazyl (DPPH), and $\alpha$-tocopherol were purchased from Sigma Chemical Co. (St. Louis, MO). Isovitexin, orientin, and vitexin were purchased from Fluka Chemika-Biochemika Co. (Ronkonkoma, NY). Isoorientin was obtained from Chromadex Co. (Daimler St., Santa Ana, CA). Pyrogallol was obtained from Merck Co. (Darmstadt, Germany).

Plant Materials and Growth Conditions. Buckwheat seed was immersed in water for $6 \mathrm{~h}$ and then put into a bag for germination for $12-15 \mathrm{~h}$. The seed was then sown in a plate with sandy soil $(35 \times 25$ $\times 3 \mathrm{~cm})$. The plate was put in an incubator $(\mathrm{HOTECH}$, model $624 \mathrm{HD}$ LE-539, Taipei, Taiwan) with $12 \mathrm{~h}$ fluorescent lighting at $25 \pm 2{ }^{\circ} \mathrm{C}$ everyday. Water spray was conducted at an interval of $4 \mathrm{~h}$ from $8 \mathrm{am}$ to $8 \mathrm{pm}$ everyday. The water used to grow buckwheat was TEW with concentrations of 100,200,300,400, and $500 \mathrm{ppm}$, while deionized water (DIW) was used as the control. After 6-7 days, buckwheat sprouts (about 5-7 cm) were harvested and freeze-dried. Dried buckwheat sprouts were milled and stored at $4{ }^{\circ} \mathrm{C}$ for $3-5$ days.

Composition Determination. The analysis of the protein, lipid, moisture, ash, and fiber contents of buckwheat sprouts was performed according to standard AOAC methods (16).

Determination of Trace Elements. Freeze-dried buckwheat sprout powder ( $3 \mathrm{~g}$ ), DIW or $300 \mathrm{ppm}$ of TEW, was mixed with $10 \mathrm{~mL}$ of $70 \%$ nitric acid and digested in a closed digestion oven. After being liquefied, the sample volume was adjusted to $50 \mathrm{~mL}$ and analyzed by inductively coupled plasma mass spectrometry (ICP-MS; Agilent Technologies 7500C, Tokyo, Japan). Cu, Zn, Se, Mn, and Fe were used as the reference materials to determine their contents in DIW, $300 \mathrm{ppm}$ of TEW, and the buckwheat sprouts.

Preparation of the Ethanolic Extract from Buckwheat Sprouts. Freeze-dried buckwheat sprout powder $(10 \mathrm{~g})$ was extracted twice with $100 \mathrm{~mL}$ of ethanol each time (total $200 \mathrm{~mL}$ ) at $80^{\circ} \mathrm{C}$ for $3 \mathrm{~h}$ using a rotary vacuum evaporator (EYELA N-N series; Tokyo Rikakikai Co., Ltd., Tokyo, Japan). The ethanolic solution was filtered with Whatman No.1 paper, and then ethanol was removed in an evaporator at a temperature lower than $40{ }^{\circ} \mathrm{C}$. The residue was freeze-dried (EYELA FDU-540; Tokyo Rikakikai Co., Ltd., Tokyo, Japan) and stored at -20 ${ }^{\circ} \mathrm{C}$ until use. The freeze-dried residue served as the sample for subsequent tests with three duplicates.

Determination of Flavonoid Compounds with HPLC Analysis. Buckwheat sprout powder or the ethanolic extract was dissolved in methanol and filtered with nylon filters $(0.45 \mu \mathrm{m})$. The contents of isoorientin, vitexin, isovitexin, and rutin in the mixtures were determined using high-performance liquid chromatography (HPLC) (Hewlett Packard series 1100; Agilent Technologies, Inc., Santa Clara, CA) with an internal standard, pyrogallol. The conditions for HPLC were as follows: column, Zorbax 80A Extend C18 $(5 \mu \mathrm{m}, 4.6 \times 250 \mathrm{~mm}$; Agilent Technologies, Inc., Santa Clara, CA); temperature of column, $25{ }^{\circ} \mathrm{C}$; amount of injection, $5 \mu \mathrm{L}$; flow rate, $1 \mathrm{~mL} / \mathrm{min}$; ultraviolet detector, $254 \mathrm{~nm}$. The mobile phases were water (Milli-Q, 18.2 M 2 ) (mobile phase A) and methanol-acetic acid (95:5 v/v) (mobile phase B). The gradient conditions were mobile phase B reaching $20 \%, 40 \%$, $50 \%, 70 \%$, and $100 \%$ at $10,20,30,40$, and $50 \mathrm{~min}$, respectively.

Determination of Reducing Power. The reducing power of the ethanolic extract from buckwheat sprout was determined according to the method of Oyaizu (17). The extract $(1 \mathrm{~mL}, 0.3-10 \mathrm{mg} / \mathrm{mL})$ was mixed with an equal volume of $0.2 \mathrm{M}$ phosphate buffer $(\mathrm{pH}$ 6.6) and $1 \%$ potassium ferricyanide and then incubated at $50{ }^{\circ} \mathrm{C}$ for $20 \mathrm{~min}$. After cooling the mixture in an ice bath to about ambient temperature, $1 \mathrm{~mL}$ of $10 \%$ trichloroacetic acid was added to the mixture to stop the reaction, and then the mixture was centrifuged at $2500 \mathrm{~g}$ for $10 \mathrm{~min}$. The supernatant $(1 \mathrm{~mL})$ of the mixture was mixed with $1 \mathrm{~mL}$ of distilled water and $0.2 \mathrm{~mL}$ of $0.1 \% \mathrm{FeCl}_{3}$, and then the absorbance was measured at $700 \mathrm{~nm}$. The reducing powers of the tested samples increased with the absorbance values. Ascorbic acid, $\alpha$-tocopherol, and BHT were used as positive controls.
Determination of DPPH Radical Scavenging Activity. DPPH radical scavenging activity was measured according to the method of Shimada et al. (18) with slight modification. The ethanolic extract (1 $\mathrm{mL}$ ) was blended with $1 \mathrm{~mL}$ of $1 \mathrm{mM} \mathrm{DPPH}$ (in methanol); then the mixture was shaken vigorously and left in the dark at room temperature for $30 \mathrm{~min}$. The absorbance of the resultant solution was measured spectrophotometrically at $517 \mathrm{~nm}$. The DPPH radical scavenging activity was calculated as follows: \% scavenging activity $=\left[\left(A_{0}-(A\right.\right.$ $\left.\left.\left.-A_{\mathrm{b}}\right)\right) / A_{0}\right] \times 100$, where $A_{0}$ is the value of DPPH without sample, $A$ is the value of the sample with DPPH, and $A_{\mathrm{b}}$ is the value of the sample without DPPH. Ascorbic acid, $\alpha$-tocopherol, and BHT were used as positive controls.

Determination of Ferrous Ion Chelating Activity. Ferrous ion chelating activity of the sample solution was determined by the method of Dinis (19). The sample solution $(2 \mathrm{~mL})$ was mixed with $0.6 \mathrm{~mL}$ of deionized water and $0.1 \mathrm{~mL}$ of $1 \mathrm{mM} \mathrm{FeCl}_{2}$ and then allowed to sit at room temperature for $30 \mathrm{~s}$. The reaction was initiated by the addition of $0.2 \mathrm{~mL}$ of $2.5 \mathrm{mM}$ ferrozine for $10 \mathrm{~min}$; the absorbance of the mixture was measured at $562 \mathrm{~nm}$. The $\%$ chelating activity $=[1-$ (sample $A_{562 \mathrm{~nm}} /$ blank $\left.\left.\mathrm{A}_{562 \mathrm{~nm}}\right)\right] \times 100$.

Determination of Superoxide Anion Scavenging Activity. Superoxide anion scavenging activity of the ethanolic extract from buckwheat sprout was based on the method described by Roback and Gryglewski (20) with slight modification. One milliliter of nitro blue tetrazolium solution (150 $\mu \mathrm{M}$ in $100 \mathrm{mM}$ phosphate buffer, $\mathrm{pH} 7.4), 1 \mathrm{~mL}$ of NADH solution ( $468 \mu \mathrm{M}$ in $100 \mathrm{mM}$ phosphate buffer, $\mathrm{pH} 7.4)$, and $0.1 \mathrm{~mL}$ of the ethanolic extract from buckwheat sprout were mixed. The reaction was started by adding $100 \mu \mathrm{L}$ of phenazine methosulfate solution (60 $\mu \mathrm{M}$ in $100 \mathrm{mM}$ phosphate buffer, $\mathrm{pH}$ 7.4) to the mixture. The reaction mixture was incubated at $25^{\circ} \mathrm{C}$ for $5 \mathrm{~min}$, and the absorbance at 560 $\mathrm{nm}$ was measured against blank samples. Decreased absorbance of the reaction mixture indicated increased superoxide anion scavenging activity. The percentage inhibition of superoxide anion generation was calculated using the formula: \% scavenging activity $=\left[\left(A_{0}-A_{1}\right) / A_{0}\right]$ $\times 100$, where $A_{0}$ was the absorbance of the control (ethanol) and $A_{1}$ was the absorbance of the buckwheat sprout extract.

Determination of the Inhibitory Activity toward Lipid Peroxidation. The antioxidant activity was determined according to the method described by Misuda et al. (21) with some modification. A 2.5 $\mathrm{mL}$ aliquot of $0.02 \mathrm{M}$ linoleic acid emulsion $(0.2804 \mathrm{~g}$ of linoleic acid and $0.2804 \mathrm{~g}$ of Tween $20 \mathrm{in} 50 \mathrm{~mL}$ of phosphate buffer, $\mathrm{pH}$ 7.0) was mixed with $0.5 \mathrm{~mL}$ of ethanolic extract from buckwheat sprout and 2 $\mathrm{mL}$ of $0.2 \mathrm{M}$ phosphate buffer $(\mathrm{pH} 7.0)$. After incubation at $50{ }^{\circ} \mathrm{C}$ in the dark for $72 \mathrm{~h}$, a $0.1 \mathrm{~mL}$ aliquot of the reaction solution was mixed with $4.7 \mathrm{~mL}$ of ethanol (75\%), $0.1 \mathrm{~mL}$ of ammonium thiocyanate (30\%), and $0.1 \mathrm{~mL}$ of ferrous chloride $(20 \mathrm{mM})$. After the mixture was stirred for $3 \mathrm{~min}$, the peroxide value was determined by reading the absorbance at $500 \mathrm{~nm}$, and the inhibition percent of linoleic acid peroxidation was calculated as \% inhibition $=[1-($ absorbance of sample at $500 \mathrm{~nm}) /$ (absorbance of control (ethanol) at $500 \mathrm{~nm}$ ) $] \times 100$. Ascorbic acid, $\alpha$-tocopherol, and BHT $(0.1 \mathrm{mg} / \mathrm{mL})$ were used as positive controls.

Cell Culture. Human hepatoma Hep G2 cells were purchased from the Food Industry Research and Development Institute, Hsinchu, Taiwan. The cells were grown in a humidified incubator (90\% humidity) with $5 \% \mathrm{CO}_{2}$ at $37{ }^{\circ} \mathrm{C}$. They were grown in DMEM medium from Biowhitaker (Innogenetics, Madrid, Spain), supplemented with $10 \%$ Biowhitaker fetal bovine serum (FBS). The cells were usually split $1: 4$ when they reached $80 \%$ confluence.

Determination of Cell Viability. The cells were plated in 96-well plates at an initial cell count of $1 \times 10^{4}$ per well and incubated at 37 ${ }^{\circ} \mathrm{C}$ in $5 \% \mathrm{CO}_{2}$. After being treated with different concentrations $(0.05-1$ $\mathrm{mg} / \mathrm{mL}$ ) of $100 \mu \mathrm{L}$ of ethanolic extract from buckwheat sprout for 24-72 $\mathrm{h}$, the cells were incubated with $2 \mathrm{mg} / \mathrm{mL}$ MTT $(100 \mu \mathrm{L})$ for $2.5 \mathrm{~h}$. Then the intracellular formazan product was dissolved in DMSO (100 $\mu \mathrm{L}$ ) and quantified with an ELISA reader at $570 \mathrm{~nm}$.

Determination of Antioxidant Enzyme Activity. The cells were plated in $60 \mathrm{~mm}$ diameter plates at a concentration of $4 \times 10^{6}$ per plate and incubated at $37{ }^{\circ} \mathrm{C}$ in $5 \% \mathrm{CO}_{2}$. The cells were pretreated with $5 \mathrm{~mL}$ of $0.5 \mathrm{mg} / \mathrm{mL}$ ethanolic extract from buckwheat sprout for $6 \mathrm{~h}$. Then the plate was washed with phosphate-buffered saline (PBS) twice. The cells were collected and broken by an ultrasonic processor, 
and then the supernatant was collected by centrifugation at $24000 g$ for $4{ }^{\circ} \mathrm{C}$ for $30 \mathrm{~min}$ (Sorvall RC 5C PLUS centrifuge; Global Medical Instrumentation, Inc., Ramsey, MN). Superoxide dismutase (SOD) activity was determined by the commercial RANSOD SD-125 assay kit (Randox Laboratories Ltd., Ardmore, U.K.), while GPx activity was determined by the RANSEL RS-504 assay kit (Randox Laboratories Ltd., Ardmore, U.K.).

Determination of Intracellular Reactive Oxygen Species (ROS) and Superoxide Anion. The intracellular ROS production was measured using the nonfluorescent compound $2^{\prime}, 7^{\prime}$-dichlorofluorescein diacetate (DCFH-DA) (22). When this compound enters viable cells, it can be deacetylated to form $2^{\prime}, 7^{\prime}$-dichlorofluorescein (DCFH) which can react quantitatively with ROC within the cell to produce $2^{\prime}, 7^{\prime}$-dichlorofluorescein (DCF), which is fluorescent. In flow cytometry, DCF can produce green fluorescence $(535 \mathrm{~nm})$ and provide an index of intracellular oxidation (23). Superoxide anion can oxidize a membranepermeable substrate, dihydroethidium (DHE), to form a fluorescent compound, ethidium. In flow cytometry, ethidium can produce red fluorescence $(605 \mathrm{~nm})$ and provide an index of the intracellular level of superoxide anion.

The cells were plated in $60 \mathrm{~mm}$ diameter plates at a concentration of $4 \times 10^{6}$ per plate and incubated at $37{ }^{\circ} \mathrm{C}$ in $5 \% \mathrm{CO}_{2}$. The cells were pretreated with $5 \mathrm{~mL}$ of $0.5 \mathrm{mg} / \mathrm{mL}$ ethanolic extract from buckwheat sprout for $3,6,9$, and $12 \mathrm{~h}$. Then $2 \mathrm{~mL}$ of $10 \mu \mathrm{M} \mathrm{DCFH}-$ DA or DHE was added and further incubated for $30 \mathrm{~min}$. Then the plate was washed with PBS twice. The cells were collected in a 15 $\mathrm{mL}$ centrifuge tube and then centrifuged at $2500 \mathrm{~g}$ for $5 \mathrm{~min}$ to remove the supernatant. Finally, $0.7 \mu \mathrm{L}$ of PBS was used to transfer the cells to a polypropylene conical tube. ROS and superoxide anion measurements were performed using a flow cytometer (fluorescence-activated cell sorter, FACS Calibur flow cytometer; Becton Dickinson, San Jose, CA) with the CellQuest software.

Statistical Analysis. All data were in triplicate and expressed as the mean \pm standard deviation. Analysis of variance was performed by ANOVA procedures (Figures 1, 2, and 3). Duncan's multiple-range test was used to determine the difference of means, and $p<0.05$ was considered to be statistically significant. Student's $t$ test was used to determine the difference between two means (Tables 1 and 2).

\section{RESULTS AND DISCUSSION}

Effects of TEW Concentrations on the Antioxidant Activities of Ethanolic Extracts from Buckwheat Sprouts. Figure 1 shows the antioxidant activities of ethanolic extracts $(1 \mathrm{mg} /$ $\mathrm{mL}$ ) from buckwheat sprout grown in DIW and TEW at 100, $200,300,400$, and $500 \mathrm{ppm}$. It was found that buckwheat sprout grown in TEW at $300 \mathrm{ppm}$ had the highest reducing power, DPPH radical scavenging activity, ferrous ion chelating activity, and inhibitory activity toward lipid peroxidation. Further increase of the concentration of TEW could result in a decline in the antioxidative activities. However, the concentration of TEW showed no significant effect on the superoxide anion scavenging activity. Therefore, we considered that TEW at 300 ppm could result in the highest antioxidant activity of buckwheat sprout. Thus, for the subsequent tests, we only selected 300 ppm of TEW as the experimental factor using DIW as control. The yields of the ethanolic extraction from buckwheat sprouts grown at DIW and $300 \mathrm{ppm}$ of TEW were not significantly different, $20.5 \pm 2.7 \%$ and $21.5 \pm 0.9 \%$, respectively.

Trace Element Contents, Composition, and Flavonoid Contents of Buckwheat Sprout. We determined the amounts of $\mathrm{Cu}, \mathrm{Zn}, \mathrm{Se}, \mathrm{Mn}$, and Fe because they might relate to the antioxidant ability. Their contents in $300 \mathrm{ppm}$ of TEW and buckwheat sprout are shown in Table 1. All five trace elements were significantly different between TEW and DIW. In buckwheat sprout, all of the trace elements also differed between TEW and DIW groups with the exception of Se. The ratios of TEW/DIW for $\mathrm{Cu}, \mathrm{Zn}, \mathrm{Se}, \mathrm{Mn}$, and Fe in the buckwheat sprout were $1.2,1.07,1.0,1.05$, and 1.19 , respectively. The result indicated that the increase of these trace elements in buckwheat sprout was due to the supplement of TEW. Therefore, it brought us to consider that the possible harmful trace elements presented in TEW might also be absorbed by buckwheat. So the amount of $\mathrm{Cr}, \mathrm{As}, \mathrm{Cd}, \mathrm{Hg}$, and $\mathrm{Pb}$ in TEW was also determined, and the data are shown in Table 2. It was found that all of the tested heavy metal contents did not differ between TEW and DIW with the exception of $\mathrm{Cr}$ content. Although the $\mathrm{Cr}$ content in TEW was 1.4-fold of that in DIW, the amount $(1.6 \mu \mathrm{g} / \mathrm{g})$ was not a problem in terms of safety consideration.

The moisture, protein, fat, fiber, and ash contents of buckwheat sprout grown at $300 \mathrm{ppm}$ of TEW were $92.1 \%, 0.16 \%$, $0.39 \%, 0.73 \%$, and $0.77 \%$ on a wet weight basis, respectively. There were no significant differences in moisture, crude protein, crude fat, and crude fiber contents between the buckwheat sprouts grown in $300 \mathrm{ppm}$ of TEW and DIW. However, the ash content of the sprouts grown in $300 \mathrm{ppm}$ of TEW was 1.13 times of that in the DIW group.

Four different flavonoid compounds were found in buckwheat sprout from TEW; their contents followed the order rutin $(2.57$ $\mathrm{mg} / \mathrm{g})>$ isoorientin $(1.27 \mathrm{mg} / \mathrm{g})>\operatorname{vitexin}(0.11 \mathrm{mg} / \mathrm{g})>$ isovitexin $(0.04 \mathrm{mg} / \mathrm{g})$. All of the flavonoid compounds did not differ between fresh buckwheat sprouts grown in TEW and DIW. Moreover, in the ethanolic extracts, all of the flavonoid contents were similar in TEW and DIW groups (data not shown).

Antioxidant Activities of Ethanolic Extracts from Buckwheat Sprouts. Antioxidant activities of the ethanolic extracts from buckwheat sprout grown in TEW (300 ppm) and DIW were determined at six concentrations, 0.31, 0.63, 1.25, 2.5, 5, and $10 \mathrm{mg} / \mathrm{mL}$. There was no significant difference in the reducing power between the ethanolic extracts from buckwheat sprouts grown in TEW and DIW (Figure 2A). When compared to ascorbic acid, $\alpha$-tocopherol, and BHT, the reducing power in buckwheat sprout was lower than ascorbic acid and BHT but higher than $\alpha$-tocopherol. For DPPH radical scavenging activity, we also found no significant difference between the TEW and DIW groups (Figure 2B). However, the TEW group showed significantly higher ferrous ion chelating activity than the DIW group $(p<0.05)$ in all concentrations except $2.5 \mathrm{mg}$ / $\mathrm{mL}$ (Figure 2C). Since $\alpha$-tocopherol and BHT do not have a metal ion chelating functional group, they showed poor ferrous ion chelating activity. Our data also showed that ascorbic acid did not have the ability to bond ferrous ion. It has been pointed out that metal ions from $\mathrm{FeCl}_{3}, \mathrm{CuCl}_{2}$, or $\mathrm{FeCl}_{2}$ can promote the peroxidation of ascorbic acid and decrease its ferrous ion chelating activity (24). Both the TEW and DIW groups showed low superoxide anion scavenging activities, and no significant difference was found between the two groups (Figure 2D). Ascorbic acid had high superoxide anion scavenging activity, but $\alpha$-tocopherol and BHT did not show inhibitory activity toward the superoxide anion. In fact, Kim et al. (25) even reported that $\alpha$-tocopherol and BHT promoted the production of the superoxide anion. The ability to inhibit the lipid peroxidation was higher in the TEW group than in the DIW group $(p<0.01)$ at the concentration range of $0.31-1.25 \mathrm{mg} /$ $\mathrm{mL}$. It was found that the inhibitory activity of the ethanolic extract from buckwheat sprout was similar to that of $\alpha$-tocopherol but lower than those of ascorbic acid and BHT (Figure 2E).

In general, our data indicated that the ethanolic extract from buckwheat sprout showed high reducing power, DPPH radical scavenging activity, ferrous ion chelating activity, and inhibitory activity toward lipid peroxidation but poor superoxide anion 

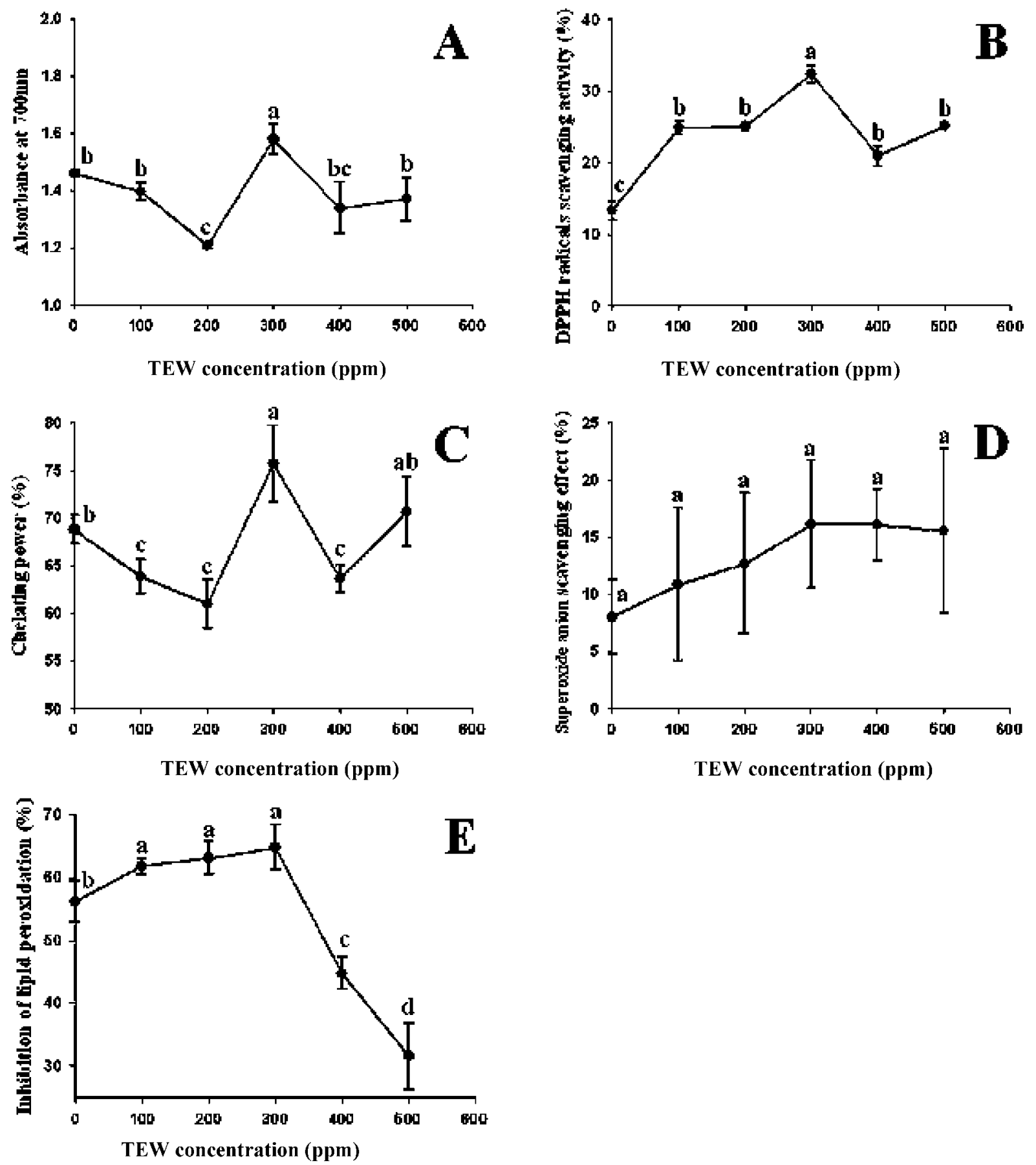

Figure 1. Effects of the concentrations of trace element water on the antioxidative activities of the ethanolic extracts from buckwheat sprout $[(\mathrm{A})$ reducing power, (B) DPPH radical scavenging activity, (C) ferrous ion chelating ability, (D) superoxide anion scavenging activity, and (E) inhibition toward lipid peroxidation]. The values are the mean $(n=3)$, and the error bars are standard deviations. $a, b, c, d$ : values followed by different superscripts are significantly different $(p \geq 0.05)$.

scavenging activity. In addition, buckwheat sprout grown in the TEW group had higher ferrous ion chelating activity and inhibitory activity toward lipid peroxidation than the sprout grown in the DIW group. Since the levels of rutin and other tested flavonoid compounds did not differ between buckwheat sprouts grown in TEW and DIW, but the levels of some tested trace elements did increase in the TEW group, the higher antioxidant activity in the TEW group might be due to some of the trace elements in TEW. We also recorded the weights and highs of buckwheat sprouts from the TEW and DIW groups, and the results indicated that the highs of the sprouts did not differ between TEW and DIW groups but the weights of the sprout from TEW were higher than that from DIW (data not shown). It was possible that the growth rate of the sprouts in the TEW group was higher than that of the DIW group, and thus they accumulate higher contents of trace elements and affected the antioxidant activity.

Cell Viability. Effects of the ethanolic extracts from buckwheat sprouts grown in TEW and DIW on the viability of the human Hep G2 cell were tested at five different concentrations, $0.05,0.1,0.2,0.5$, and $1 \mathrm{mg} / \mathrm{mL}$. At low concentrations, 0.05 and $0.1 \mathrm{mg} / \mathrm{mL}$, both of the ethanolic extracts in TEW and DIW groups showed no cytotoxicity toward human Hep G2 cell. At high concentrations, 0.5 and $1 \mathrm{mg} / \mathrm{mL}$, the cell viabilities were lower than $60 \%$ in both of the extracts in TEW and DIW. We selected the concentration of $0.2 \mathrm{mg} / \mathrm{mL}$ for the subsequent tests 

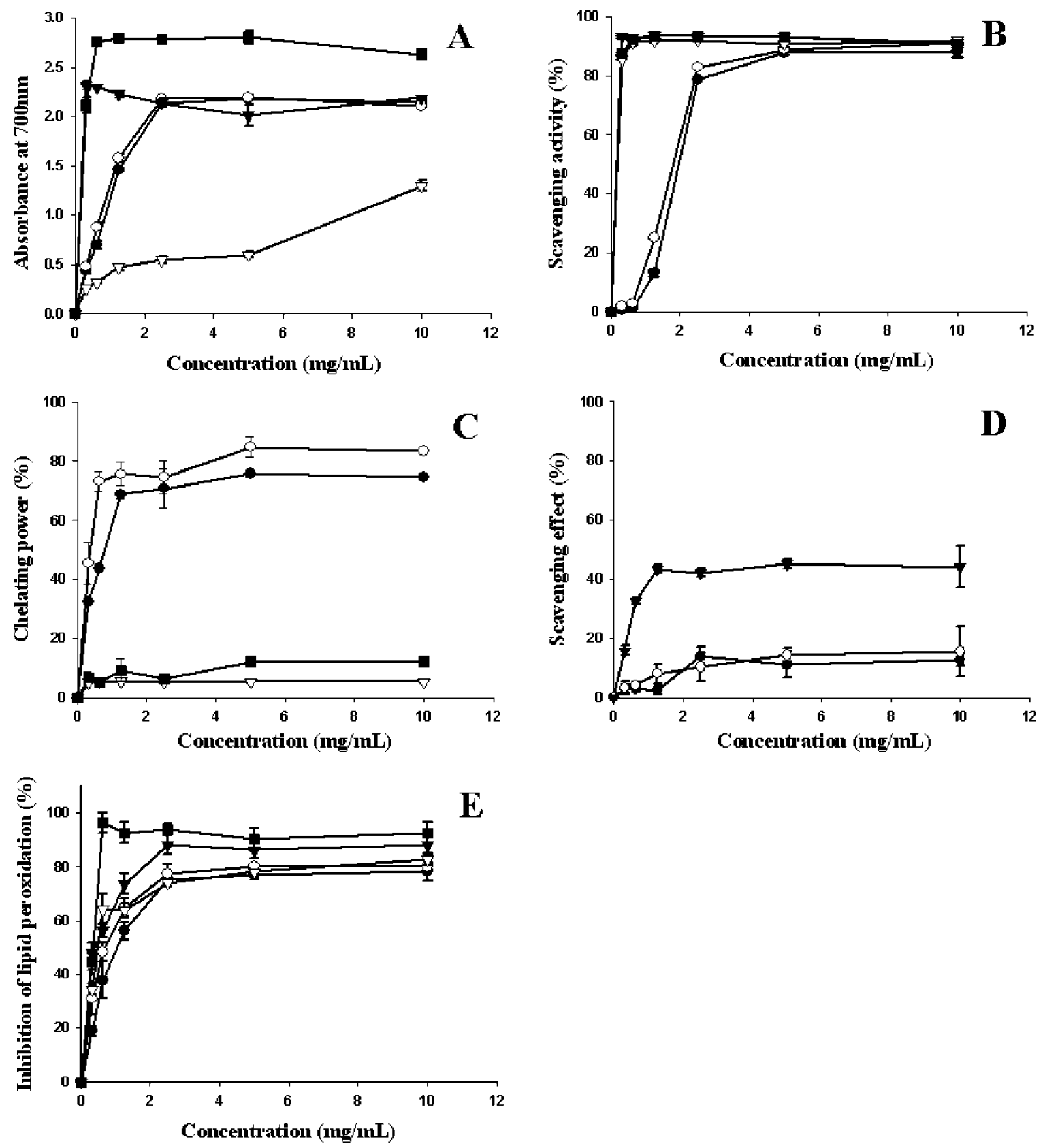

$\rightarrow$ DIW group; $\rightarrow$ TEW group; $\rightarrow$ ascorbic acid; $\rightarrow \alpha$-tocopherol; $\rightarrow$ BHT

Figure 2. Antioxidative activities of the ethanolic extract of buckwheat sprout grown in DIW and TEW [(A) reducing power, (B) DPPH radical scavenging activity, (C) ferrous ion chelating ability, (D) superoxide anion scavenging activity, and (E) inhibition toward lipid peroxidation]. The values are the mean $(n=3)$, and the error bars are standard deviations.

for evaluating the antioxidant status in the human Hep G2 cell because the cell viability was maintained higher than $80 \%$ up to $72 \mathrm{~h}$. It was also noted that the effect of the extract from buckwheat sprout did not differ between TEW and DIW groups in all tested concentrations.

Intracellular Activities of SOD and GPx. The human Hep G2 cell was pretreated with $0.2 \mathrm{mg} / \mathrm{mL}$ ethanolic extracts in TEW and DIW groups for 3, 6, 9, and $12 \mathrm{~h}$. The effect of the extracts on the intracellular SOD activity was determined, and the data are shown in Figure 3A. It was found that the pretreatment of the extracts significantly increased the SOD activity. When the extracts were pretreated for 9 and $12 \mathrm{~h}$, the SOD activity was higher in the TEW group than that in the
DIW group. This might be because the buckwheat sprout in the TEW group had higher trace elements, such as $\mathrm{Cu}, \mathrm{Zn}$, and $\mathrm{Mn}$, that could promote the SOD activity. As shown in Figure 3B, pretreatment of the extracts at 6 and $9 \mathrm{~h}$ increased the GPx activity in the human Hep G2 cell; however, no significant difference was found between the extracts in TEW and DIW groups. It has been shown that Se can influence GPx activity $(14,26)$. It was suspected that the amount of Se did not differ in buckwheat sprout grown in TEW and DIW; therefore, no difference was found in the GPx activity.

Intracellular ROS and Superoxide Anion. The fluorescence intensity of DCF was used as the index to represent the amount of the intracellular ROS level in the human Hep G2 cell. Both 

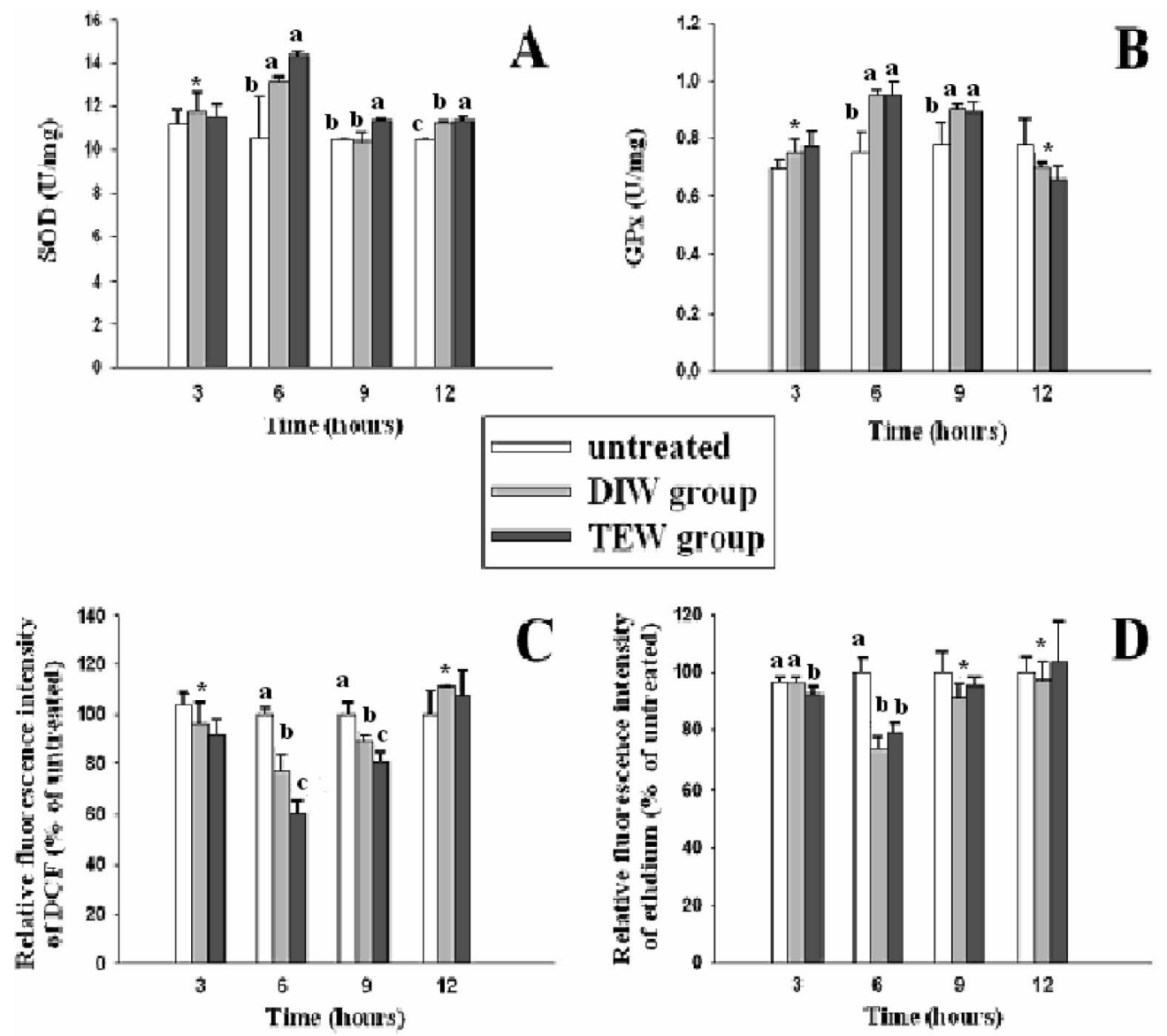

Figure 3. Effect of the ethanolic extract from buckwheat sprout on the antioxidant enzyme activity and oxide in the human Hep G2 cell [(A) superoxide dismutase (SOD) activity, (B) glutathione peroxidase (GPx) activity, (C) reactive oxygen species (ROS) based on the relative fluorescence intensity of 2,7-dichlorofluorescein (DCF), and (D) superoxide anion based on the relative fluorescence intensity of ethidium]. The values are the mean, and the error bars are standard deviations. Asterisks indicate that the values within each sampling time are not significantly different $(p>0.05)$. $a, b, c$ : values followed by different superscripts are significantly different in each sampling time $(p<0.05)$.

Table 1. Contents of Trace Elements in Trace Element Water (at 300 ppm), Deionized Water, and Buckwheat Sprouts ${ }^{a}$

\begin{tabular}{|c|c|c|c|c|c|}
\hline & $\mathrm{Cu}(\mu \mathrm{g} / \mathrm{g})$ & $\operatorname{Zn}(\mu \mathrm{g} / \mathrm{g})$ & Se $(\mu \mathrm{g} / \mathrm{g})$ & $\mathrm{Mn}(\mu \mathrm{g} / \mathrm{g})$ & $\mathrm{Fe}(\mu \mathrm{g} / \mathrm{g})$ \\
\hline \multicolumn{6}{|l|}{ water } \\
\hline DIW & $0.30 \pm 0.00^{\mathrm{a}}$ & $8.76 \pm 0.00^{\mathrm{a}}$ & $0.13 \pm 0.04^{a}$ & $0.15 \pm 0.00^{\mathrm{a}}$ & $1.01 \pm 0.01^{\mathrm{a}}$ \\
\hline TEW & $2.42 \pm 0.00^{\mathrm{b}}$ & $37.24 \pm 0.00^{b}$ & $0.28 \pm 0.03^{\mathrm{b}}$ & $49.77 \pm 0.02^{b}$ & $2391 \pm 0.00^{\mathrm{b}}$ \\
\hline DIW group & $0.62 \pm 0.03^{\mathrm{a}}$ & $3.23 \pm 0.05^{\mathrm{a}}$ & $0.01 \pm 0.00^{\mathrm{a}}$ & $4.19 \pm 0.07^{a}$ & $11.03 \pm 0.75^{\mathrm{a}}$ \\
\hline TEW group & $0.77 \pm 0.03^{b}$ & $3.44 \pm 0.06^{b}$ & $0.01 \pm 0.00^{\mathrm{a}}$ & $4.40 \pm 0.02^{\mathrm{b}}$ & $13.18 \pm 0.08^{b}$ \\
\hline
\end{tabular}

\footnotetext{
${ }^{a}$ The contents are presented on a wet weight basis. The values are the mean \pm standard deviation $(n=3) . \mathrm{a}, \mathrm{b}$ : values in the same column followed by different superscripts are significantly different $(p \geq 0.05)$.
}

Table 2. Heavy Metal Contents in Buckwheat Sprouts Grown in Trace Element Water (at 300 ppm) and Deionized Water ${ }^{a}$

\begin{tabular}{|c|c|c|c|c|c|}
\hline & $\mathrm{Cr}(\mu \mathrm{g} / \mathrm{g})$ & As $(\mu \mathrm{g} / \mathrm{g})$ & $\mathrm{Cd}(\mu \mathrm{g} / \mathrm{g})$ & $\mathrm{Hg}(\mu \mathrm{g} / \mathrm{g})$ & $\mathrm{Pb}(\mu \mathrm{g} / \mathrm{g})$ \\
\hline DIW group & $1.11 \pm 0.22^{a}$ & $0.002 \pm 0.000^{a}$ & $0.004 \pm 0.000^{\mathrm{a}}$ & $0.002 \pm 0.001^{a}$ & $0.010 \pm 0.004^{a}$ \\
\hline TEW group & $1.59 \pm 0.04^{\mathrm{b}}$ & $0.002 \pm 0.000^{\mathrm{a}}$ & $0.004 \pm 0.003^{a}$ & $0.00 \pm 0.000^{a}$ & $0.006 \pm 0.000^{\mathrm{a}}$ \\
\hline
\end{tabular}

\footnotetext{
superscripts are significantly different $(p \geq 0.05)$.

of the extracts in the TEW and DIW groups reduced the production of ROS when the cell was pretreated with the extracts for 6 and $9 \mathrm{~h}$ (Figure 3C). It was noted that the extract in TEW was more effective in reducing the ROS levels at 6 and $9 \mathrm{~h}$. These findings agreed with higher SOD activities found in the TEW group at 9 and $12 \mathrm{~h}$ (Figure 3A) because in the TEW group SOD might convert ROS to hydrogen peroxide more effectively. Our data indicated that the supplement of TEW to buckwheat increased the activity of SOD and, thus, reduced
}

${ }^{a}$ The contents are presented on a wet weight basis. The values are the mean \pm standard deviation $(n=3)$. a, b: values in the same column followed by different

the levels of ROS in the human Hep G2 cell. At 3 and 6 h, the extracts from buckwheat sprouts grown in TEW significantly decreased the level of superoxide anion in the cell (Figure 3D). However, the production of intracellular superoxide anion did not vary between TEW and DIW groups with the exception of lower concentration of superoxide anion in the TEW group at $3 \mathrm{~h}$.

Our data indicated that the use of trace element water for the growth of buckwheat increased the antioxidant activity of buckwheat sprout. Therefore, it was reasonable to consider that 
trace elements could influence the antioxidant activities. Although it was still unclear whether the key trace elements were responsible for the increase of the antioxidant activities, we had demonstrated that the beneficial effect of trace elements on the antioxidant activity could be accomplished with the supplement at appropriate amounts of trace element water.

\section{LITERATURE CITED}

(1) Halliwell, B.; Gutteridge, J. M. C. Protection against oxidants in biological system: the superoxide theory of oxygen toxicity. In Free Radical in Biology and Medicine; Halliwell, B., Gutteridge, J. M. C., Eds.; Clarendon Press: Oxford, U.K., 1989; pp 86-123.

(2) Kreft, I.; Fabjan, N.; Yasumoto, K. Rutin content in buckwheat (Fagopyrum esculentum Moench) food materials and products. Food Chem. 2006, 98, 508-512.

(3) Park, C. H.; Kim, Y. B.; Choi, Y. S.; Heo, K.; Kim, S. L.; Lee, K. C. Rutin content in food products processed from groats, leaves and flowers of buckwheat. Fagopyrum 2000, 17, 63-66.

(4) Kreft, S.; Knapp, M.; Kreft, I. Extraction of rutin from buckwheat (Fagopyrum esculentum Moench) seeds and determination by capillary electrophoresis. J. Agric. Food Chem. 1999, 46, 20202023.

(5) Abeywardena, M. Y.; Head, R. J. Dietary polyunsaturated fatty acid and antioxidant modulation of vascular dysfunction in the spontaneously hypertensive rat. Prostaglandins, Leukotrienes, Essent. Fatty Acids 2001, 65, 91-97.

(6) Wojcicki, J.; Barcew-Wiszniewska, B.; Samochowiec, L.; Rozewicka, L. Extractum Fagopyri reduces artheriosclerosis in high-fat diet fed rabbits. Pharmazie 1995, 50, 560-562.

(7) Prohaska, J. R.; Luckasewycz, O. A. Copper deficiency suppresses the immune response of mice. Science 1981, 213, 559-561.

(8) Roussel, A. M.; Anderson, R. A.; Favier, A. E. Trace elements in man and animals; Kluwer Academic/Plenum Publishers: New York, 2000.

(9) Steinman, H. M. Superoxide dismutase: Protein chemistry and structure-function relationships. In Superoxide Dismutase; Oberley, L. W., Ed.; CRC Press: Boca Raton, FL, 1982; Vol. I, pp 11-68.

(10) Wichtel, J. J. A review of selenium deficiency in grazing ruminants Part 1: new roles for selenium in ruminant metabolism. N. Z. Vet. J. 1998, 46, 47-52.

(11) Geret, F.; Bebianno, M. J. Does zinc produce reactive oxygen species in Ruditapes decussates? Ecotoxicol. Environ. Saf. 2004, 57, 399-409.

(12) Mukhopadhay, M. J.; Sharma, A. Manganese in cell metabolism of higher plants. Bot. Rev. 1991, 57, 117-149.
(13) McCall, K. A.; Huang, C.; Fierke, C. A. Function and mechanism of zinc metalloenzymes. J. Nutr. 2000, 130, 1437S-1446S.

(14) Tinggi, U. Essentiality and toxicity of selenium and its status in Australia; a review. Toxicol. Lett. 2003, 137, 103-110.

(15) Shimanishi, A. Rockwater-its manufacturing, characteristics and applications. In Rockwater; Kubota, S., Ed.; Technical Publisher: Toykuyo, Japan, 1997; pp 3-20.

(16) AOAC. Official Methods of Analysis, 16th ed.; Association of Official Analytical Chemists: Washington, DC, 1997.

(17) Oyaizu, M. Antioxidative activity of browing products of glucomamine fractional by organic solvent and Thinlayer chromatograph. Nippon Shokuhin Kogyo Gakkaish 1986, 35, 771-775.

(18) Shimada, K.; Fujikawa, K.; Yahara, K.; Nakamura, T. Antioxidative properties of xanthine on the autoxidation of soybean oil in cyclodextrin emulsion. J. Agric. Food Chem. 1992, 40, 945948.

(19) Dinis, T. C.; Maderia, V. M.; Almeda, L. M. Action of phenolic derivatives (acetaminophen, salicylate and 5-aminosalicylate) as inhibitors of membrane lipid peroxidation and as peroxyl radical scavengers. Arch. Biochem. Biophys. 1994, 315, 161-169.

(20) Roback, J.; Gryglewski, R. J. Flavonoids are scavengers of superoxide anions. Biochem. Pharmacol. 1988, 17, 837-841.

(21) Misuda, H.; Yasumoto, K.; Iwami, K. Antioxidative action of indole compounds during the autooxidation of linoleic acid. Eiyo to Shokuryo 1966, 19, 210-214.

(22) LeBel, C. P.; Ishiropoulos, H.; Bondy, S. C. Evaluation of the probe $2^{\prime}, 7^{\prime}$-dichlorofluorescein as an indicator of reactive oxygen species formation and oxidative stress. Chem. Res. Toxicol. 1992, $5,227-231$.

(23) Wang, H.; Joseph, J. A. Quantifying cellular oxidative stress by dichlorofluorescein assay using microplate reader. Free Radical Biol. Med. 1999, 27, 612-616.

(24) Satoh, K.; Sakagami, H. Effect of metal ions on radical intensity and cytotoxic activity of ascorbate. Anticancer Res. 1997, 17, $1125-1130$.

(25) Kim, S. J.; Han, D.; Moon, K. D.; Rhee, J. S. Measurement of superoxide dismutase-like activity of natural antioxidant. Biosci., Biotechnol., Biochem. 1995, 59, 822-826.

(26) Brigelius, F. R. Tissue-specific functions of individual glutathione peroxidase. Free Radical Biol. Med. 1999, 27, 951-965.

Received for review June 3, 2007. Revised manuscript received August 24, 2007. Accepted August 27, 2007.

JF0716275 